\title{
Electrocardiographic T-wave parameters in families with long QT syndrome
}

\author{
Grażyna Markiewicz-Łoskot 1,A-D,F, Ewa Moric-Janiszewska 2,B,C,F, Bogusław Mazurek ${ }^{3, B, C}$, \\ Marianna Łoskot ${ }^{4, B-F}$, Mariola Bartusek ${ }^{1, F}$, Agnieszka Skierska ${ }^{3, B}$, Lesław Szydłowski ${ }^{3, C, E, F}$ \\ ${ }^{1}$ Department of Nursing and Social Medical Problems, School of Health Sciences in Katowice, Medical University of Silesia in Katowice, Poland \\ 2 Department of Biochemistry, School of Pharmacy with the Division of Laboratory Medicine in Sosnowiec, Medical University of Silesia in Katowice, Polan \\ ${ }^{3}$ Department of Pediatric Cardiology, School of Medicine in Katowice, Medical University of Silesia in Katowice, Poland \\ ${ }^{4}$ Department of Nursing and Social Medical Problems, Students' Research Group, School of Health Sciences in Katowice, Medical University of Silesia in Katowice, Poland \\ A - research concept and design; B - collection and/or assembly of data; C - data analysis and interpretation; \\ $D$ - writing the article; $E$ - critical revision of the article; $F$ - final approval of the article
}

\begin{abstract}
Address for correspondence
Ewa Moric-Janiszewska

E-mail: ejaniszewska@sum.edu.pl

\section{Funding sources}

The study was supported by the Medical

University of Silesia in Katowice through

a grant No. KNW-1-020/P/2/0.
\end{abstract}

\section{Conflict of interest}

None declared

Received on August 12, 2016

Reviewed on December 27, 2016

Accepted on January 12, 2017

\begin{abstract}
Background. T-wave parameters, especially the Tpeak-Tend interval (TpTe), reflect the total dispersion of repolarization, whose amplification may lead to the development of life-threatening ventricular arrhythmias observed in the long QT syndrome (LQTS).

Objectives. The study attempted to evaluate QT, QTp (Q-Tpeak) and TpTe (Tpeak-Tend) intervals in unaffected and affected blood relatives of children with clinically confirmed LQTS as well as to determine whether the values of these repolarization parameters may be used in clinical practice.

Material and methods. The study group included 47 affected blood relatives (27 LQTS1 and 20 LQTS2) and 68 unaffected family members without clinically confirmed LQTS symptoms. The TpTe, QT and QTp intervals were measured manually in the lead V5 of standard ECGs and corrected using Bazett's and Fridericia's formulas.

Results. The RR, QT, QTp and TpTe intervals with their corrected values were significantly longer $(\mathrm{p}<0.0001)$ in the affected subjects than in the unaffected subjects and, similarly, in LQTS1 and LQTS2 patients compared with the unaffected family members. The TpTe interval in LQTS2 showed only a tendency to be longer compared to LQTS1, but did not reach statistical significance $(p=0.0933)$. For affected blood relatives, only the TpTe interval $(p<0.0409)$ and QT interval, corrected with Bazett's $(p<0.0393)$ and Fridericia's $(p<0.0495)$ formulas, enabled differentiation between LQTS1 (mean TpTe $=103 \pm 15)$ and LQTS2 women (mean TpTe $=106 \pm 17)$. Moreover, there were statistically significant differences $(p<0.05)$ in the TpTe interval between the 6 sex subgroups: unaffected women and men as well as women and men with LQTS1 and LQTS2.

Conclusions. The electrocardiographic Tpeak-Tend parameter, in addition to the QT interval, is helpful in identifying affected blood relatives of children with LQTS, particularly for the group of LQTS1 and LQTS2 women. Further studies are required to assess the clinical importance of the TpTe interval in families with long QT syndrome.
\end{abstract}

Key words: repolarization, long QT syndrome, QT, Q-Tpeak, Tpeak-Tend intervals

DOI

10.17219/acem/68441

\section{Copyright}

Copyright by Author(s)

This is an article distributed under the terms of the

Creative Commons Attribution Non-Commercial License

(http://creativecommons.org/licenses/by-nc-nd/4.o/) 


\section{Introduction}

Congenital long QT syndrome (LQTS) is a disease manifested by electrocardiographic repolarization abnormalities with the QT interval prolongation and predisposition for malignant ventricular tachyarrhythmias (torsade de pointes), potentially leading to recurrent syncope and sudden cardiac death (SCD). ${ }^{1}$

Among 15 types of LQTS mutations thus far identified, the most common LQTS1 (KCNQ1) and LQTS2 (KCNH2) genotypes differ in the clinical course, symptom-related triggers, duration and morphology of the repolarization wave in the ECG, determined by various action potential durations in cardiac myocytes, dependent on malfunctioning ion channels: slowly repolarizing cardiac potassium current $\mathrm{I}_{\mathrm{Ks}}$ in LQTS1 and rapidly repolarizing cardiac potassium current $\mathrm{I}_{\mathrm{Kr}}$ in LQTS2. ${ }^{2-5}$

The criteria for LQTS diagnosis, valid since 1993 (improved in 2012) and comprising a point scale (the Schwartz score $\geq 4$ ), based on clinical presentation, family history and the electrocardiographic analysis of the QT interval, do not include the classification of the most common types of LQTS: LQTS1 and LQTS2.1,6 Moreover, the criteria do not consider the diagnostic importance of the QTp (Q-Tpeak) and TpTe (Tpeak-Tend) intervals in the resting and exercise ECG that help differentiate between LQTS1 and LQTS2 and assess the risk of malignant ventricular arrhythmias. $^{7-12}$

T-wave parameters, especially the Tpeak-Tend (TpTe) interval, may provide a more accurate electrophysiological marker of ventricular arrhythmia risk than the QT interval. ${ }^{12,13}$ The question of whether TpTe reflects transmural repolarization heterogeneity or total dispersion of repolarization is still a matter of debate. . $^{5,14-16}$

The study attempted to evaluate the QT, QTp and TpTe intervals in unaffected and affected blood relatives of children with long QT syndrome as well as to determine whether the values of these repolarization parameters may be used in clinical practice as a possible method of identifying affected and unaffected subjects, and whether they may help differentiate between LQTS1 and LQTS2 types.

\section{Material and methods}

Thirty-five unrelated families with long QT syndrome (each with 2 generations of members) were enrolled into the study. This group consisted of 115 adult blood relatives of 62 children with clinically diagnosed LQTS (35 children with LQTS1 and 27 with LQTS2) who were admitted to the Department of Pediatric Cardiology of the Medical University of Silesia in Katowice (Poland). Based on the ECG analysis of the repolarization period as well as clinical presentation, personal and family history of syncope and arrhythmia and/or aborted SCD, the study group included 47 adult blood relatives with LQTS and 68 unaffected family members without clinically confirmed LQTS symptoms. All the affected patients had score values $\geq 4$ according to the Schwartz and Moss criteria. ${ }^{1}$

The affected family members were 27 patients with LQTS1 and 20 patients with LQTS2. Identification of the most common LQTS1 or LQTS2 in the patients with long QT syndrome was based on the analysis of the repolarization period: morphology, amplitude and duration of the T-wave in the standard ECG (in LQTS1, T-wave: broad-based, smooth, with a higher amplitude; in LQTS2, T-wave: bifid, notched, flat, with long duration) (Fig. 1, 2), and a history of genotype-specific triggers (sympathetic stimulation in LQTS1: mainly exertion - particularly swimming, emotional stress, cardiac events - usually during rest; in LQTS2: sudden arousal from rest or sleep, auditory stimuli). ${ }^{5}$

In order to search for mutations, genomic DNA was obtained from all patients, using $\mathrm{mSSCP}$ and sequencing. Furthermore, the transcriptional activity of the encoding genes KCNQ1 and KCNH2 (HERG) was determined in the study, using the quantitive real-time polymerase chain-reaction (QRT-PCR). The expression of the investigated genes was inferred from the analysis of the number of mRNA copies per $1 \mu \mathrm{g}$ total mRNA isolated from whole blood. The genetic data was presented in earlier papers. ${ }^{17,18}$

The study exclusion criteria were bundle branch block or any other intraventricular conduction defect, atrial fibrillation, lack of sinus rhythm, and use of medications known to prolong the QT interval.

In the study, digital 12-lead resting electrocardiograms of 115 blood relatives were recorded at a paper speed of $50 \mathrm{~mm} / \mathrm{s}$ with an amplification of $10 \mathrm{~mm} / \mathrm{mV}$ (AT2 plus Schiller AG, Baar, Switzerland).

The RR, QT, QTp, and TpTe intervals were measured manually in the lead V5 of standard ECG in 3 consecutive cardiac cycles, and then averaged. The QT interval was measured from the onset of $\mathrm{Q}$-wave to the end of T-wave at the point of its return to the isoelectric line. The end of T-wave was defined as the intersection between the line tangent to the descending arm of T-wave and the isoelectric line. The QTp was the interval between the Q onset and T-wave peak. The TpTe was the interval from the peak of T-wave to the end of T-wave at the point of its return to the isoelectric line. If T-wave was inverted, the TpTe interval was measured from the lowest point of the inverted T-wave to the end of T-wave at the point of its return to the isoelectric line. The U-wave was not taken into account. ${ }^{19}$ The RR interval was measured on the basis of an average of 3 cardiac cycles (the same cycles in which the QTp and TpTe intervals were measured). To correct for possible heart rate effects on QT and QTp, we applied

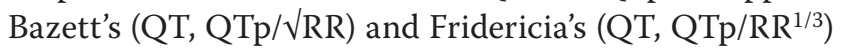
formulas. All measurements of the end of T-wave were analyzed blindly by another independent investigator, without access to the obtained results and clinical data. 


\section{Statistical analysis}

The data was exported from an Excel v. 2010 datasheet to the STATISTICA v. 7.1 data analysis software system (StatSoft Inc. 2006, Kraków, Poland). Due to the lack of normal distribution of the investigated parameters, examined with the Shapiro-Wilk test, we used the Mann-Whitney U test. Variables that followed normal distribution were compared using the Student's t-test. In addition, the ANOVA test (Kruskal-Wallis test) and post hoc test (Student-Newman-Keuls) were used for the comparison of sex subgroups (medians and ranges). The level for statistical significance was set at a $\mathrm{p}$-value $<0.05$. The $\mathrm{ROC}$ curve receiver operating characteristic (ROC) (area under curve [AUC]) analysis was also performed to find the cut-off point for the TpTe intervals with the highest sensitivity and specificity.

The study was approved by the Bioethics Committee at the Medical University of Silesia in Katowice (No. NN-6501-182/05).

\section{Results}

One hundred fifteen adult blood relatives of 62 children with clinically diagnosed LQTS were enrolled into the study: 47 adult blood relatives with LQTS ( 36 women and 11 men; mean age $41 \pm 16$ years) and 68 unaffected family members (26 women and 42 men; mean age $40 \pm 14$ years) without clinically confirmed LQTS symptoms (Table 1).

Among 27 family members with LQTS1 (22 women and 5 men; mean age $44 \pm 19$ years), 10 subjects (5 mothers, 1 father, 1 sister, 1 brother, 1 father's sister, and 1 mother's sister) were symptomatic with a history of exercise-related syncope. Two mothers had a positive family history of sudden cardiac death by the age of 30 years. Among 20 family members with LQTS2 (14 women and 6 men; mean age $36 \pm 11$ years), 3 mothers with cardiac arrest (TdP) and an implantable cardioverter-defibrillator reported recurrent syncope during pregnancy and puerperium. Twelve subjects ( 7 mothers, 2 fathers, 1 sister, 1 maternal grandmother, and 1 paternal grandmother) reported syncope, often occurring during rest and sleep, triggered by stress or auditory stimuli. In the past history of 3 LQTS2 families, cases of sudden cardiac death at a young age were reported. All subjects with cardiac events (10 with LQTS1 and 15 with LQTS2) received beta-blockers. Moreover, antiepileptic drugs were administered to 2 LQTS2 family members.

In the whole study group of 115 blood relatives, there were no significant differences $(\mathrm{p}=0.822)$ in age between the affected and unaffected family members (Table 2). However, the unaffected men (mean age $42.88 \pm 13.03$ years) were older $(\mathrm{p}=0.0494)$ than the unaffected women (mean age $36.92 \pm 15.36$ ) (Table 3 ).
Table 1. Clinical characteristics of affected and unaffected subjects

\begin{tabular}{|c|c|c|c|}
\hline \multirow[b]{2}{*}{ Study group } & \multicolumn{2}{|c|}{ Affected $(n=47)$} & \multirow{2}{*}{$\begin{array}{l}\text { Unaffected } \\
\qquad(n=68)\end{array}$} \\
\hline & $\begin{array}{l}\text { LQTS1 } \\
(n=27)\end{array}$ & $\begin{array}{l}\text { LQTS2 } \\
(n=20)\end{array}$ & \\
\hline Age [years] (mean \pm SD) & $44 \pm 19$ & $37 \pm 12$ & $40 \pm 15$ \\
\hline Range & $20-83$ & $21-54$ & $18-77$ \\
\hline Men/women & $5 / 27$ & $6 / 14$ & $42 / 26$ \\
\hline $\mathrm{RR}($ mean $\pm \mathrm{SD})$ & $810 \pm 128$ & $790 \pm 111$ & $902 \pm 135$ \\
\hline Range & $550-1120$ & 610-1000 & $600-1400$ \\
\hline QTcB (mean \pm SD) & $468 \pm 15$ & $485 \pm 37$ & $412 \pm 26$ \\
\hline Range & $450-500$ & $450-550$ & $320-450$ \\
\hline Symptomatic/asymptomatic & $10 / 17$ & $15 / 5$ & $0 / 68$ \\
\hline
\end{tabular}

values (ms) are shown as a mean \pm standard deviation (SD) and a range; QTCB QT intervals corrected for heart rate (HR) using Bazett's formula.

Table 2. Electrocardiographic characteristics of unaffected and affected subjects

\begin{tabular}{|c|c|c|c|c|c|}
\hline \multirow{2}{*}{$\begin{array}{c}\text { ECG } \\
\text { parameters }\end{array}$} & \multicolumn{2}{|c|}{$\begin{array}{l}\text { Unaffected } \\
\qquad(n=68)\end{array}$} & \multicolumn{2}{|c|}{$\begin{array}{l}\text { Affected } \\
(n=47)\end{array}$} & \multirow[t]{2}{*}{$p$-value } \\
\hline & mean & $\mathrm{SD}$ & mean & SD & \\
\hline AGE [years] & 40.60 & 14.15 & 41.19 & 16.78 & 0.8222 \\
\hline HR [beats/min] & 67.95 & 10.13 & 76.30 & 11.44 & 0.0001 \\
\hline$R R$ & 902 & 135 & 802 & 120 & 0.0001 \\
\hline QT & 389 & 25 & 424 & 39 & $<0.0001$ \\
\hline QTcB & 412 & 26 & 475 & 27 & $<0.0001$ \\
\hline QTCF & 404 & 22 & 457 & 28 & $<0.0001$ \\
\hline QTp & 304 & 21 & 316 & 31 & 0.0080 \\
\hline QTpcB & 322 & 22 & 353 & 24 & $<0.0001$ \\
\hline QTpcF & 315 & 19 & 340 & 25 & $<0.0001$ \\
\hline TpTe & 85 & 15 & 109 & 17 & $<0.0001$ \\
\hline
\end{tabular}

values [ms] are shown as a mean \pm standard deviation (SD); QTcB, QTpcB - QT,

QTp intervals corrected for heart rate (HR) using Bazett's formula; QTcF,

QTpcF - QT, QTp intervals corrected for heart rate (HR) using Fridericia's formula.

Table 3. Electrocardiographic characteristics of unaffected women and unaffected men

\begin{tabular}{|c|c|c|c|c|c|}
\hline \multirow{2}{*}{$\begin{array}{c}\text { ECG } \\
\text { parameters }\end{array}$} & \multicolumn{2}{|c|}{$\begin{array}{l}\text { Unaffected women } \\
\qquad(n=26)\end{array}$} & \multicolumn{2}{|c|}{$\begin{array}{l}\text { Unaffected men } \\
\qquad(n=42)\end{array}$} & \multirow{2}{*}{$p$-value } \\
\hline & mean & SD & mean & SD & \\
\hline Age [years] & 36.92 & 15.36 & 42.88 & 13.03 & 0.0494 \\
\hline HR [beats/min] & 70.32 & 9.88 & 66.48 & 10.13 & 0.1074 \\
\hline$R R$ & 870 & 123 & 923 & 140 & 0.1074 \\
\hline QT & 388 & 27 & 390 & 25 & 0.7932 \\
\hline QTcB & 418 & 33 & 408 & 21 & 0.0945 \\
\hline QTCF & 408 & 28 & 402 & 17 & 0.1915 \\
\hline QTp & 305 & 22 & 303 & 21 & 0.8518 \\
\hline QTpcB & 329 & 26 & 317 & 18 & 0.0227 \\
\hline QTpcF & 321 & 22 & 312 & 16 & 0.0486 \\
\hline TpTe & 83 & 17 & 87 & 13 & 0.1446 \\
\hline
\end{tabular}

values [ms] are shown as a mean \pm standard deviation (SD); QTcB, QTpcB - QT, QTp intervals corrected for heart rate (HR) using Bazett's formula; QTcF, QTpcF QT, QTp intervals corrected for heart rate (HR) using Fridericia's formula. 


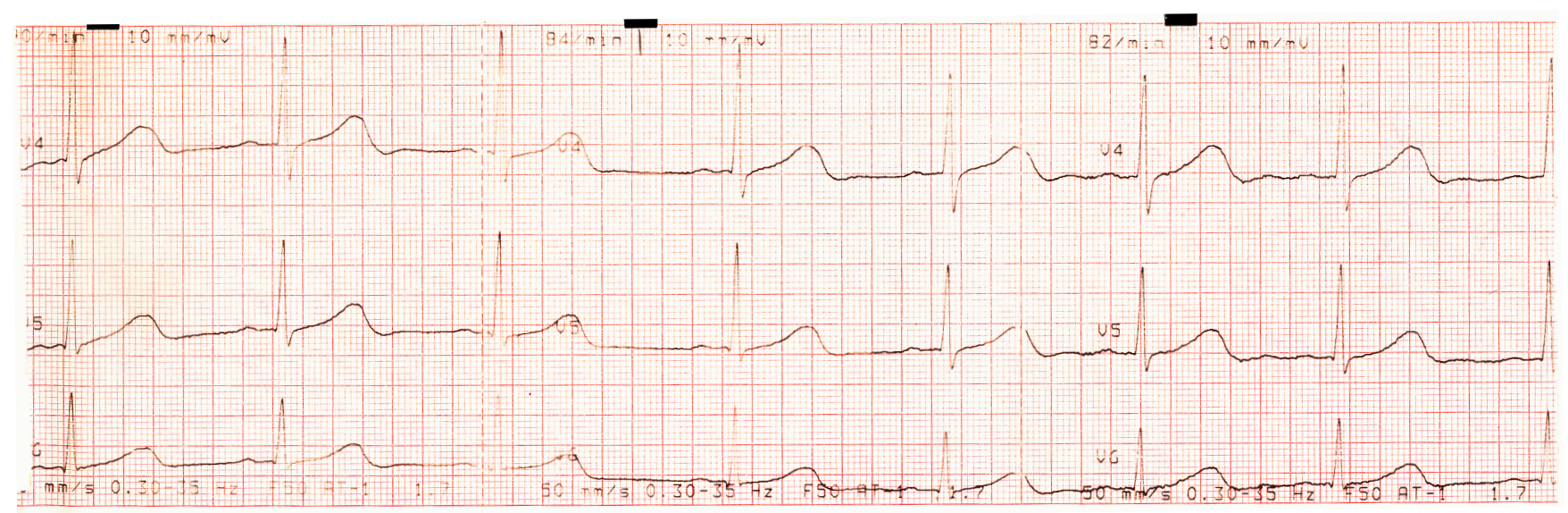

Fig. 1. Precordial leads (V4-V6) in the ECG of LQTS1 patient. Broad-based T-wave. TpTe:100 ms, QTcB: 456 ms

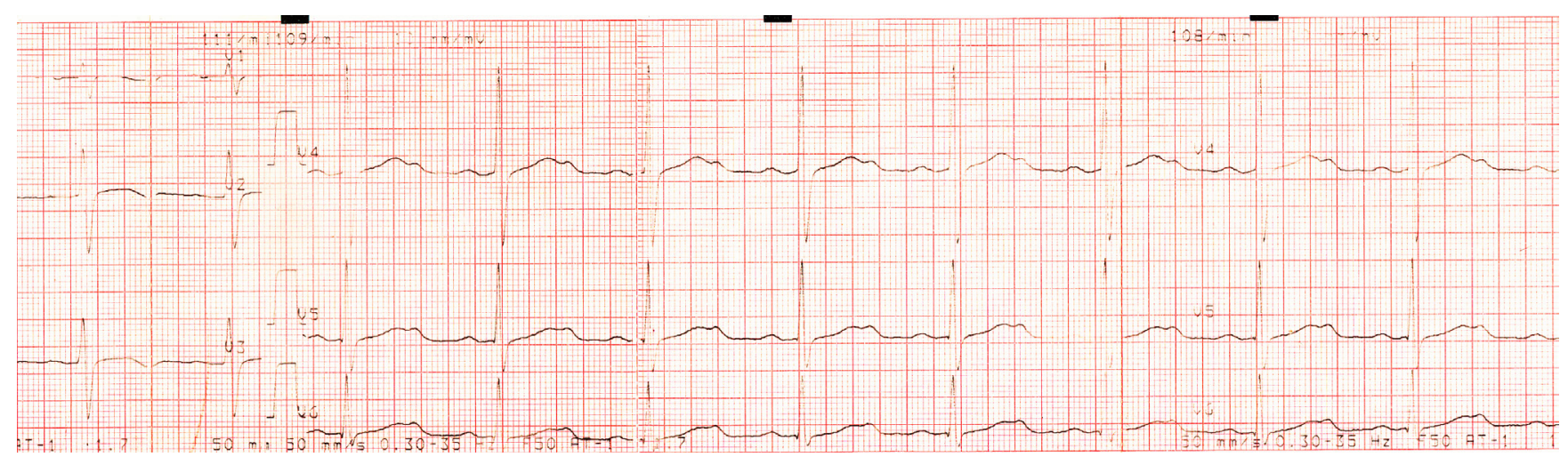

Fig. 2. Precordial leads (V4-V6) in the ECG of LQTS2 patient. Bifid T-wave. TpTe: 140 ms, QTcB: 481 ms

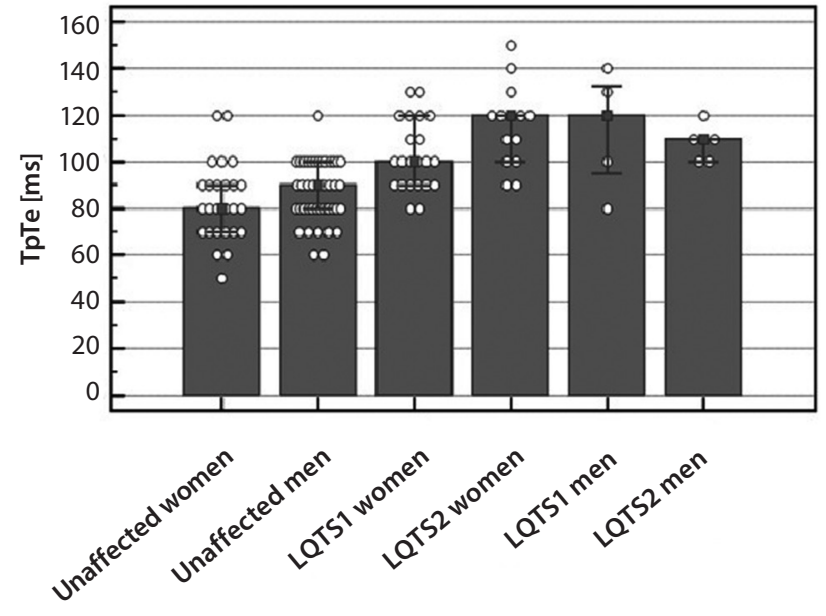

Fig. 3. Statistically significant differences $(p<0.05)$ in the TpTe intervals between the 6 sex subgroups: 1 - unaffected women; 2 - unaffected men; 3 - LQTS1 women; 4 - LQTS2 women; 5 - LQTS1 men; 6 - LQTS2 men. Values [ms] are shown as a median and a range

All the subjects presented sinus rhythm. Heart rates in the unaffected blood relatives varied from 42 to 100 beats/min, while in the affected subjects, the values ranged from 53 to 109 beats/min (Table 1). The RR intervals were significantly longer $(\mathrm{p}=0.0001)$ in the unaffected subjects than in the affected subjects (Table 2).
The baseline TpTe intervals and the QT, QTp intervals (ms) with their values corrected using Bazett's (QTcB, QT$\mathrm{pcB}$ ) and Fridericia's (QTcF, QTpcF) formulas were significantly greater in the affected than in the unaffected subjects $(\mathrm{p}<0.0001)$ (Table 2$)$.

There were no sex differences in the TpTe intervals and QT, QTp intervals with their corrected values between the unaffected women and unaffected men, except the QT$\mathrm{pcB}(\mathrm{p}=0.0227)$ and QTpcF $(\mathrm{p}=0.0486)$, and in the affected women compared with the affected men, except the QTcB (p = 0.0394) and QTpcB ( $=0.0108)$ (Tables 3, 4).

The LQTS1 and LQTS2 patients showed significantly longer ( $\mathrm{p}<0.0001)$ mean TpTe, QT, QTp intervals and higher corrected values than the unaffected family members, except the QTp in LQTS1 ( $=0.0714)$.

The RR, QT and QTp intervals with their corrected values showed no statistically significant differences between the LQTS1 and LQTS2 types (Table 5). The TpTe interval in LQTS2 showed a tendency to be longer compared to LQTS1, but did not reach statistical significance $(p=0.0933)$. However, the TpTe interval showed statistically significant sex differences between the LQTS1 and LQTS2 women ( $\mathrm{p}=0.0409)$ (Table 6). In addition, QTcB $(\mathrm{p}=0.0393)$ and QTcF $(\mathrm{p}=0.0495)$ values were significantly greater in the women with LQTS2 than in LQTS1 women (Table 6). 
The age of 5 men with LQTS1 varied from 20 to 74 years, TpTe - from 80 to $140 \mathrm{~ms}$; the age of 6 men with LQTS2 varied from 28 to 54 years, TpTe - from 100 to $120 \mathrm{~ms}$.There were no significant differences between the LQTS1 and LQTS2 men in the RR, TpTe intervals and the QT and QTp intervals with their corrected values. Moreover, there were statistically significant differences $(\mathrm{p}<0.05)$ in the TpTe interval between the 6 sex subgroups: unaffected women and men as well as women and men with LQTS1 and LQTS2 (Fig. 3). The area under the ROC curve (AUC) for the TpTe intervals of the LQTS1 and LQTS2 women was 0.705 , indicating that this variable is a relatively good discriminator. The cut-off point for the TpTe intervals that optimizes the values of sensitivity and specificity is for values $\geq 100 \mathrm{~ms}$ (Fig. 4).

\section{Discussion}

The ventricular repolarization analysis has been shown to be effective in identifying electrical myocardial instability that leads to the development of ventricular arrhythmia (TdP) observed in the long QT syndrome. In clinical evaluation, the last part of total T-wave (the TpTe interval) has been found to be amplified in patients with congenital long QT syndrome and acquired LQTS. ${ }^{13,20-23}$ The TpTe interval has been suggested to reflect repolarization heterogeneity that can be easily demonstrated in a standard electrocardiogram (ECG). ${ }^{24}$

Therefore, in clinical practice, the TpTe interval is considered a more sensitive marker of arrhythmogenesis compared with the QT interval. ${ }^{13,20,23}$

In families of LQTS patients, measurements of the Tpeak-Tend interval (TpTe) seemed to be important for the identification of affected relatives, but this parameter did not distinguish symptomatic from asymptomatic subjects. $8,12,25$

The present study showed that the LQTS-affected patients (LQTS1 and LQTS2) had significantly longer QT, QTp and TpTe intervals than the unaffected family members, which may possibly contribute to the increased risk of cardiac events, although we did not evaluate the association of repolarization parameters, such as TpTe, with cardiac events.

Similarly, Viitasalo et al. (revision Holter recordings) and Kanters et al. (ECG analysis) described increased TpTe intervals in patients with LQTS2 compared with LQTS1 subjects or unaffected family members, but they could not find significant differences between symptomatic and asymptomatic patients in any group. ${ }^{25}$
Table 4. Electrocardiographic characteristics of affected women and affected men

\begin{tabular}{|l|c|c|c|c|c|}
\multirow{2}{*}{\begin{tabular}{l}
\multirow{2}{*}{ ECG } \\
parameters
\end{tabular}} & \multicolumn{2}{|c|}{$\begin{array}{c}\text { Affected women } \\
(\mathrm{n}=36)\end{array}$} & \multicolumn{2}{c|}{$\begin{array}{c}\text { Affected men } \\
(\mathrm{n}=11)\end{array}$} & \multirow{2}{*}{ p-value } \\
\cline { 2 - 6 } & mean & SD & mean & SD & \\
\hline Age [years] & 42.06 & 16.63 & 38.36 & 17.78 & 0.4739 \\
\hline HR [beats/min] & 76.51 & 9.16 & 75.63 & 17.55 & 0.4435 \\
\hline RR & 794 & 96 & 825 & 183 & 0.4662 \\
\hline QT & 426 & 34 & 416 & 52 & 0.5977 \\
\hline QTcB & 479 & 29 & 461 & 14 & 0.0394 \\
\hline QTcF & 461 & 28 & 445 & 24 & 0.1254 \\
\hline QTp & 319 & 27 & 305 & 43 & 0.5718 \\
\hline QTpcB & 358 & 24 & 337 & 16 & 0.0108 \\
\hline QTpcF & 344 & 24 & 326 & 24 & 0.0808 \\
\hline TpTe & 108 & 17 & 111 & 16 & 0.5299 \\
\hline
\end{tabular}

values [ms] are shown as a mean \pm standard deviation (SD); QTcB, QTpcB - QT, QTp intervals corrected for heart rate (HR) using Bazett's formula; QTcF, QTpcF - QT, QTp intervals corrected for heart rate (HR) using Fridericia's formula.

Table 5. Electrocardiographic characteristics of LQTS1 and LQTS2 subjects

\begin{tabular}{|l|c|c|c|c|c|}
\multirow{2}{*}{\begin{tabular}{l}
\multirow{2}{*}{ ECG } \\
parameters
\end{tabular}} & \multicolumn{2}{|c|}{ LQTS1 $(n=27)$} & \multicolumn{2}{c|}{ LQTS2 $(n=20)$} & \multirow{2}{*}{ p-value } \\
\cline { 2 - 5 } & mean & SD & mean & SD & \\
\hline Age [years] & 44.41 & 19.33 & 36.85 & 11.65 & 0.3276 \\
\hline HR [beats/min] & 75.73 & 12.13 & 77.07 & 10.71 & 0.6827 \\
\hline RR & 810 & 128 & 790 & 111 & 0.6748 \\
\hline QT & 420 & 37 & 430 & 41 & 0.3662 \\
\hline QTcB & 468 & 15 & 485 & 37 & 0.2917 \\
\hline QTcF & 451 & 19 & 465 & 35 & 0.2917 \\
\hline QTp & 315 & 30 & 316 & 34 & 0.5186 \\
\hline QTpcB & 351 & 20 & 356 & 29 & 0.6436 \\
\hline QTpcF & 339 & 21 & 342 & 30 & 0.4322 \\
\hline TpTe & 105 & 17 & 114 & 15 & 0.0933 \\
\hline
\end{tabular}

values [ms] are shown as a mean \pm standard deviation (SD); QTcB, QTpcB - QT, QTp intervals corrected for heart rate (HR) using Bazett's formula; QTcF, QTpcF - QT, QTp intervals corrected for heart rate (HR) using Fridericia's formula.

Table 6. Electrocardiographic characteristics of LQTS1 and LQTS2 women

\begin{tabular}{|l|c|c|c|c|c|}
\multirow{2}{*}{\begin{tabular}{l}
\multirow{2}{*}{ ECG } \\
parameters
\end{tabular}} & \multicolumn{2}{|c|}{ LQTS1 women $(\boldsymbol{n}=22)$} & \multicolumn{2}{c|}{ LQTS2 women $(\mathrm{n}=14)$} & \multirow{2}{*}{ p-value } \\
\cline { 2 - 5 } Age [years] & mean & SD & mean & SD & \\
\hline HR [beats/min] & 46.14 & 18.28 & 35.64 & 11.50 & 0.1047 \\
\hline RR & 75.98 & 9.40 & 77.33 & 9.05 & 0.7090 \\
\hline QT & 800 & 101 & 786 & 91 & 0.7333 \\
\hline QTcB & 418 & 30 & 439 & 38 & 0.1118 \\
\hline QTcF & 468 & 15 & 497 & 37 & 0.0393 \\
\hline QTp & 451 & 17 & 477 & 35 & 0.0495 \\
\hline QTpcB & 315 & 26 & 324 & 29 & 0.1888 \\
\hline QTpcF & 353 & 21 & 366 & 29 & 0.1487 \\
\hline TpTe & 103 & 21 & 351 & 27 & 0.1398 \\
\hline
\end{tabular}

values [ms] are shown as a mean \pm standard deviation (SD); QTcB, QTpcB - QT, QTp intervals corrected for heart rate (HR) using Bazett's formula; QTcF, QTPcF - QT, QTp intervals corrected for heart rate (HR) using Fridericia's formula. 
The TpTe interval seems to be a useful electrocardiographic parameter that helps differentiate between LQTS1 and LQTS2 types in resting or exercise ECG. ${ }^{7-9,12,25}$

Our previous study suggests that in diagnostic classification of long QT syndrome as LQTS1 or LQTS2 type in affected children, the most valuable electrocardiographic parameter is the TpTe interval assessed during rest and during the recovery phase after exercise. ${ }^{7}$ In the present study of blood relatives of these children, heart rates were comparable in LQTS1 and LQTS2 subjects as well as in LQTS1 and LQTS2 women. We observed that the measures of the TpTe and QT intervals did not provide differentiation between LQTS1 and LQTS2 types; however, the TpTe interval in LQTS2 showed a tendency to be longer compared to LQTS1, still not reaching statistical significance.

In addition, there were statistically significant differences in the TpTe interval between the 6 sex subgroups: unaffected women and men as well as women and men with LQTS1 or LQTS2.

Moreover, the TpTe interval and the corrected QT (QTcB and QTcF) values were differential parameters regarding LQTS1 and LQTS2 women. These are novel findings and similar data has not been found in the available literature to date.

The long QT syndrome is a disorder of diverse phenotypic presentation with some affected patients and their families.

The clinical Schwartz criteria, demonstrating sex-related differences in QTc prolongation, are still valid and the designation of QTc values $\geq 450 \mathrm{~ms}$ in men and $\geq 460 \mathrm{~ms}$ in women as prolonged QTc values comes from the standpoint of AHA/ACCF/HRS guidelines. ${ }^{19}$

The Schwartz score, with QT rate correction, after adding other electrocardiographic T-wave parameters (particularly TpTe and QTp), might provide the most useful clinical information with a potential for identifying patients affected by LQTS, as well as it may help differentiate between the LQTS types (LQTS1 and LQTS2 women in particular).

In addition, abnormal values of these parameters correlate well with increased arrhythmic risk.

Twelve-lead standard ECG remains the primary, cheap and most commonly used cardiac diagnostic tool that can help identify affected blood relatives and differentiate between LQTS1 and LQTS2 types, which may have implications for the management of patients with ventricular arrhythmias and the prevention of sudden cardiac death, aimed at modifying a lifestyle and avoiding specific triggers, according to 2015 ESC guidelines. $6,26,27$

Clinical usefulness of the TpTe interval with regard to identifying affected blood relatives of LQTS patients and differentiating between LQTS1 and LQTS2 types, particularly in terms of sex-related differences, seems to be an interesting issue, but needs further studies, particularly for larger groups of patients.

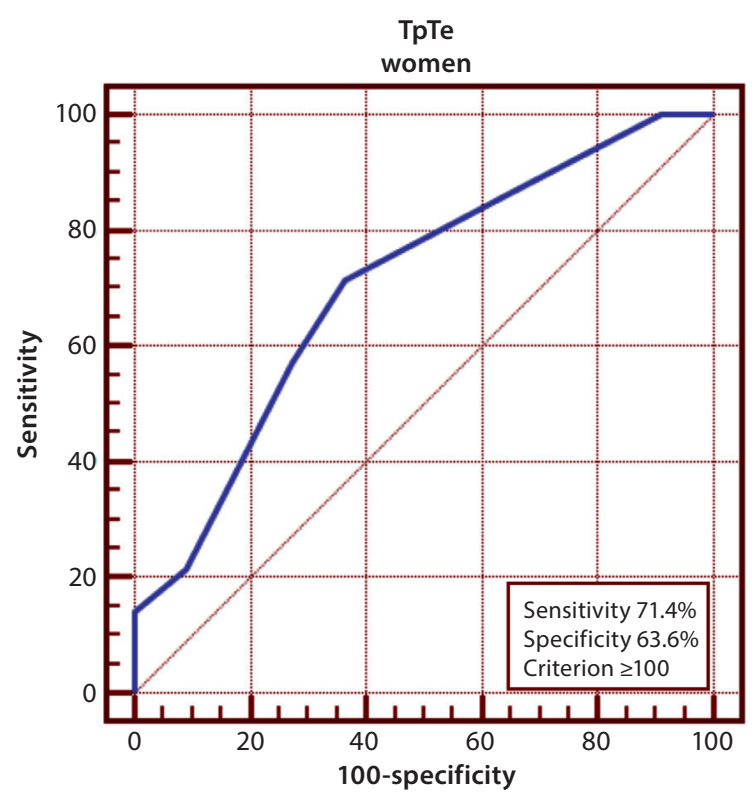

\begin{tabular}{|l|c|}
\hline Area under the ROC curve (AUC) & 0.705 \\
\hline Standard error $^{\mathrm{a}}$ & 0.0883 \\
\hline $95 \%$ confidence interval $^{\mathrm{b}}$ & $0.529-0.844$ \\
\hline z statistic & 2.317 \\
\hline Significance level p $($ area $=0.5)$ & 0.0205 \\
\hline
\end{tabular}

Fig. 4. The ROC curve (AUC) analysis for the TpTe intervals of LQTS1 and LQTS2 women. The cut-off point for the TpTe intervals that optimizes the values of sensitivity and specificity is for values $\geq 100 \mathrm{~ms}$

Based on these results, the authors conclude that the electrocardiographic Tpeak-Tend parameter, in addition to the QT interval, is helpful in identifying affected blood relatives of children with LQTS, particularly for the group of LQTS1 and LQTS2 women.

Further studies are required to assess the clinical importance of the TpTe interval in families with long QT syndrome.

\section{References}

1. Schwartz PJ, Moss AJ, Vincent GM, Crampton RS. Diagnostic criteria for the long QT syndrome: An update. Circulation. 1993;88:782-784.

2. Tester DJ, Ackerman MJ. Genetics of long QT syndrome. Methodist Debakey Cardiovasc J. 2014;10(1):29-33.

3. Schwartz PJ, Priori SG, Spazzolini C, et al. Genotype-phenotype correlation in the long QT syndrome gene-specific triggers for life-threatening arrhythmias. Circulation. 2001;103:89-95.

4. Van Langen IM, Birnie E, Alders M, Jongbloed RJ, Marec HLE, Wilde AAM. The use of genotype-phenotype correlations in mutations analysis for the long QT syndrome. J Med Genet. 2003;40:141-145.

5. Zhang L, Timothy KW, Vincent GM, et al. Spectrum of ST-T-wave patterns and repolarization parameters in congenital longQT syndrome: ECG findings identify genotype. Circulation. 2000;102:2849-2855.

6. Schwartz PJ, Ackerman MJ. The long QT syndrome: Transatlantic clinical approach to diagnosis and therapy. Eur Heart J. 2013;34:3109-3116.

7. Markiewicz-Łoskot G. Electrocardiographic characteristics of a total of repolarization (QT), early repolarization phase (QTP) and late phase repolarization (TpTe) in healthy children and children with long QT syndrome. Habilitation Dissertation. Medical University of Silesia in Katowice. 2009;8:59-76. 
8. Viitasalo M, Oikarinen L, Swan H, et al. Ambulatory electrocardiographic evidence of transmural dispersion of repolarization in patients with long QT syndrome type 1 and 2. Circulation.2002;06:2473-2478.

9. Takenaka K, Tomohiko A, Shimizu W, et al. Exercise stress test amplifies genotype-phenotype correlation in the LQT1 and LQT2 forms of the long-QT syndrome. Circulation. 2003;107:838-844.

10. Swan H, Viitasalo M, Piippo K, Laitinen P, Kontula K, Toivonen L. Sinus node function and ventricular repolarization during exercise stress test in long QT syndrome patients with KVLQT1 and HERG potassium channel defects. J Am Coll Cardiol. 1999;34:823-824.

11. Shimizu W, Tanabe Y, Aiba T, et al. Differential effects of betablockade on dispersion of repolarization in the absence and presence of sympathetic stimulation between the LQT1 and LQT2 forms of congenital long QT syndrome. J Am Coll Cardiol. 2002;39:1894-1896.

12. Extramiana F, Denjoy I, Badilini F, et al. Heart rate influences on repolarization duration and morphology in symptomatic versus asymptomatic KCNQ1 mutation carriers. Am J Cardiol. 2005;95:406-409.

13. Yamaguchi $M$, Shimizu $M$, Ino $H$, et al. T-wave peak-to-end interval and QT dispersion in acquired long QT syndrome: A new index for arrythmogenicity. Clin Sci. 2003;105:671-676.

14. Antzelevitch C. Ionic, molecular and cellular bases of QT-interval prolongation and torsade de pointes. Europace. 2007;9(4):4-15.

15. Opthof T, Coronel R, Wilms-Schopman FJG, et al. Dispersion of repolarization in canine ventricle and the electrocardiographic T-wave:Tpe interval does not reflect transmural dispersion. Heart Rhythm. 2007;4:341-348.

16. Meijborg VMF, Conrath CE, Opthof T, Belterman CNW, Bakker JMT,Coronel R. Electrocardiographic T-wave and its relation with ventricular repolarization along major anatomical axes. Circ Arrhythm Electrophysiol. 2014;7:524-531.

17. Moric-Janiszewska E, Głogowska-Ligus J, Paul-Samojedny M, et al. Expression of genes KCNQ1 and HERG encoding potassium ion channels Ikr, Iks in long QT syndrome. Kardiol Pol. 2011;5:423-429.

18. Moric-Janiszewska E, Głogowska-Ligus J, Paul-Samojedny M, Węglarz L, Markiewicz-Łoskot G, Szydłowski L. Age-and sex dependent mRNA expression of KCNQ1 and HERG in patients with long QT syndrome type 1 and 2. Arch Med Sci. 2011;6:941-947.

19. Rautaharju PM, Surawicz B, Gettes LS. AHA/ACCF/HRS recommendations for the standardization and interpretation of the electrocardiogram. Part IV: The ST segment, T- and U-waves, and the QT interval. A scientific statement from the American Heart Association Electrocardiography and Arrhythmias Committee, Council on Clinical Cardiology, the American College of Cardiology Foundation, and the Heart Rhythm Society, endorsed by the International Society for Computerized Electrocardiology. Circulation. 2009;119:241-250.

20. Lubiński A, Lewicka-NowakE, Kempa M, Baczyńska AM, Romanowska I, Świątecka G. New insight into repolarization abnormalities in patients with congenital long QT syndrome: The increased transmural dispersion of repolarization. Pacing Clin Electrophysiol. 1998;21:172-175.

21. Swan $\mathrm{H}$, Toivonen $\mathrm{L}$, Viitasalo M. Rate adaptation of QT intervals during and after exercise in children with congenital long QT syndrome. Eur Heart J. 1998;19:508-513.

22. Haapalahti P, Viitasalo M, Perhonen M, et al. Electrocardiographic interventricular dispersion of repolarization during autonomic adaptation in LQTS1 subtype of long QT syndrome. Scand Cardiovasc J. 2008;42:130-136.

23. Topilski I, Rogowski O, Rosso R, et al. The morphology of the QT interval predicts torsade de pointes during acquired bradyarrhythmias. J Am Coll Cardiol. 2007;49(3):320-328.

24. Yan GX, Antzelevitch C. Cellular basis for the normal T-wave and the electrocardiographic manifestation of the long QT syndrome. Circulation. 1998;98:1928-1936.

25. Kanters JK, Haarmark C, Vedel-Larsen E, et al. Tpeak-Tend interval in long QT syndrome. J Electrocardiol. 2008;41:603-608

26. Van Camp G, Pasquet A, Sinnaeve P, Mairesse GH, De Pauw M, Claeys MJ. Summary 2015 ESC guidelines. Acta Cardiol. 2016;71(1):7-13.

27. Markiewicz-Łoskot G, Moric-Janiszewska E, Mazurek U. The risk of cardiac events and management of LQTS patients on the basis of genotype. Ann Noninvasive Electrocardiol. 2009;14(1):86-92. 